\title{
Building Materials with Antifungal Efficacy Enriched with Silver Nanoparticles
}

\section{Marcin Banach ${ }^{1}$, Renata Szczygłowska ${ }^{2}$, Jolanta Pulit ${ }^{\star \star}$ and Mirosław Bryk ${ }^{3}$}

${ }^{1}$ Cracow University of Technology, Institute of Inorganic Chemistry and Technology, Warszawska St., 24, 31-155 Cracow, Poland

${ }^{2}$ Silesian Environmental Ph.D. Studies Centre, Central Mining Institute, Gwarków Sq, 1, 40-166 Katowice, Poland

${ }^{3}$ Implementing Company "Damiton", NadDrwina, Str., 10, 30-075 Cracow, Poland

\begin{abstract}
Microbiological tests were carried out against fungal spores (Cladosporium cladosporioides, Alternaria alternate, Rhodotorula mucilaginosa, Aspergillus Niger and Geotrichium candidum). Nanosilver suspension at a concentration of 5-15 ppm was used as a biocidal agent. It was a component of various kinds of tested paint coatings. Studies Geotrichium candidum confirmed the high biocidal efficacy thus nanosilver additive for paints and coatings makes it possible to prevent the growth of microorganisms.
\end{abstract}

Keywords: Bio deterioration; Microbial and mycological resistance; Protection coatings; Paints; Microbiological corrosion

\section{Introduction}

Applied modern construction materials, including plaster, primers and especially paints should provide adequate quality through proper maintenance and stability of the product before being installed, and in particular the health safety of the finished product which is used as a coating. The synergistic effect of various external and internal factors promotes biocorrosion, the process of destruction of building materials by microorganisms. The "Encyclopedia of Bioprocess Technology" defines biological corrosion as degradation of materials by the action of living organisms and / or their metabolic activity [1]. Most often biocorrosion is caused by bacteria and microscopic fungi, which leads to the development of biodeterioration or adverse modification and loss of optimal performance [2]. Microbial colonization in painted buildings causes aesthetic problems and may lead to degradation of the coating and splintering [3]. Much more dangerous effects may be caused by the influence of mould on human health. Spores and mycelial fragments escaping from the ground, together with bacteria and dust, form bioaerosols that are a source of air pollution. They may contain toxic compounds called mycotoxins, which cause allergies. Penicillium $s p p$, Aspergillus $s p p$ and Alternaria $s p p$ are significantly responsible for the formation of many of the allergic symptoms and respiratory diseases in people exposed to high levels of mould spores and allergens.

Penicillium $s p p$ is the most frequently isolated fungus from infected internal building environments $[4,5]$. In research conducted in archives and museums, it was found that these fungi dominated among isolated populations found on the walls and furniture (86.0-99.9\%). The most commonly isolated fungi were as follows: Alternaria $\operatorname{spp}$ (such as Alternaria alternata), Aspergillus spp (e.g. Aspergillus versicolor), Cladosporium spp (e.g. Cladosporium herbarum), Penicillium spp (e.g. Pennicillium carneum) and Rhizopus Nigricans. B. subtilis, Micrococcus species, Staphylococcus xylosus, Staphylococcus lentus, Sphingomonas paucimobilis and Pseudomonas alcaligenes were also isolated, among other bacteria [6].

Uniquely worded European requirements for building construction in terms of hygiene and sanitation as well as biological corrosion resistance were included in the European Communities Council Directive 89/106/EEC (Section 4, \&322.2) [7]. They oblige the use of materials, products and building elements that are resistant to fungus and other forms of degradation. In accordance with basic requirement No. 3 contained in the Interpretative Document on the approximation of the laws and legal acts to that Directive, building structures shall not constitute a health risk to users or the environment [8]. The fulfilment of this criterion by the product is the basis for eco-labelling, which seems particularly valuable to this developing industry in the context of promoting environmentally friendly products.

Depending on the mechanism of effective action, there are three main types of coatings: inhibiting adhesion by and preventing the formation of biofilms, gradually releasing biocides into paints and the environment, and the killing of microorganisms in the case of direct contact [9-12]. From the point of view of the need to provide and maintain an adequate anti-microbial and mycological resistance in dried paint coatings, areas of application are classified as follows: medicine, pharmacy, food and electronics (bio-clean rooms with higher requirements for resistance to antibiotic-resistant strains), facilities for public use under special physicochemical conditions: high humidity, the optimum temperature for growth of microorganisms (bathrooms, production halls, facilities in specific climatic conditions, archives, museums), Facilities for public use under normal physicochemical conditions (residences).

Selection of an appropriate antimicrobial coating for the specific area of application should therefore take into consideration its mechanism of effective action and effectiveness, the scale of the exposure to microorganisms, environmental protection and human health. Currently, in order to ensure adequate protection, active biocidal substances, which are chemicals compounds with a broad spectrum of activity that may also have harmful effects on human health and the environment, are mainly used. The concentration of biocides in paints

*Corresponding author: Jolanta Pulit, Cracow University of Technology, Institute of Inorganic Chemistry and Technology, WarszawskaSt., 24, 31-155 Cracow, Poland, Tel: +48 12 6282640; E-mail: jolanta.pulit@gmail.com

Received February 24, 2014; Accepted May 19, 2014; Published May 30, 2014

Citation: Banach M, Szczygłowska R, Pulit J, Bryk M (2014) Building Materials with Antifungal Efficacy Enriched with Silver Nanoparticles. Chem Sci J 5: 085. doi: 10.4172/2150-3494.1000085

Copyright: $\odot 2014$ Banach M, et al. This is an open-access article distributed under the terms of the Creative Commons Attribution License, which permits unrestricted use, distribution, and reproduction in any medium, provided the original author and source are credited. 
is typically $0.5 \%$ wt. Prolongation of the coating protection time can be obtained only by increasing the concentration of biocide. Water-soluble biocides are also prone to excessive leaching, thus high concentrations are used to achieve effective protection of surfaces from biodeterioration [13]. However, this may change the mechanical properties of the coating [14]. There is no universal biocide or active substance that would be compatible with all components of paints and coatings and would also meet the requirements of manufacturers. Some authors [15] suggest that in order to ensure the protection of dried waterborne coatings, twice as much of water-soluble biocides such as 2-n-octyl-4isothiazolin-3-one (OIT) and 3-iodo-2-propylbutyl carbamate (IPBC) be applied. Isothiazolinone, which is included in a standard patch test panel on contact allergies, is the most widely used biocide for paint protection. Carbendazim is a crucial biocide used to protect dry paint film, but recently introduced legal changes restrict the application of this and other products [16]. Moreover, carbendazim does not inhibit a commonly occurring fungus, Alternaria [15]. Mixtures of biocides that include combinations of fungicides and algaecides are often used to correct deficiencies in the fungicidal spectrum, e.g. IPBC + 3-(3,4-dichlorophenyl)-1,1-dimethylurea (diuron), carbendazim + diuron, carbendazim + OIT or carbendazim + IPBC. The use of silver nanoparticles as a microbiological and mycological protection in coatings can be an alternative to the use of biocides [16].

Many nano-sized substances reveal interesting new properties compared to forms with larger particle diameters. According to the literature, nanosilver has antibacterial and antifungal properties [17]. The antibacterial properties grow accordingly with increasing the total surface area of the nanoparticles and with reducing their unit dimensions. This is due to the potential for greater penetration by the particles when they are smaller in size. The effectiveness of the antibacterial properties of nanosilver also depends on the particles' shape. Triangular particles show the strongest effects [17-19]. The biocidal effects of silver nanoparticles involve binding to thiol groups located in proteins in bacterial cell membranes, which leads to an increase in membrane permeability and, consequently, to the death of the bacteria [20]. Nanoparticles less than $25 \mathrm{~nm}$ in diameter exhibited a MIC (Minimal inhibitory concentration) equal to $6.75-54 \mu \mathrm{g} / \mathrm{cm}^{3}$, while particles $25 \mathrm{~nm}$ in diameter show a MIC in the range of 16.9-13.5 $\mu \mathrm{g} /$ $\mathrm{cm}^{3}$ in relation to multiple drug-resistant bacteria such as methicillinresistant Staphylococcus aureus (MRSA) and Staphylococcus epidermidis (MRSE), as well as vancomycin-resistant Enterococcus faecium [21-25].
According to the varying degrees of effectiveness of the antimicrobial properties of nanosilver obtained via different technologies and the need to recognize the application in the coating field, researches were undertaken whose aim was to evaluate the antifungal activity of silicon paint, plaster and ground plaster containing silver nanoparticles as well as perform a mycological efficacy resistance analysis of tested preparations in relation to different concentrations of nanostructured silver. The use of nanoparticles with antimicrobial properties in construction materials can bring numerous potential advantages, such as reinforcing their hygienic properties, preventing microbial growth and maintaining their mechanical properties.

\section{Materials and Methods}

The usefulness of silver nanoparticles for bio stabilising coatings against fungi was evaluated for waterborne products that are more susceptible to fungal growth compared to products manufactured on the basis of organic solvents. Ground plaster with silver nanoparticles and the biocide ACTICIDE ${ }^{*}$ MBS, silicone plaster with silver nanoparticles and $\mathrm{ACTICIDE}^{\circ} \mathrm{MBS}$, and silicone paint with silver nanoparticles and $\mathrm{ACTICIDE}^{\circ} \mathrm{MBS}$ were used in the analysis. Silicone paint containing a protective system in the form of a mixture of silver nanoparticles and the ACTICIDE ${ }^{\circ}$ MBF 50 biocide, as well as silver nanoparticles and the ACTICIDE EPW biocide, in their shells were also examined. Data concerning the tested systems are listed in Table 1.

$\mathrm{ACTICIDE}^{\circ} \mathrm{MBF} 50$ and $\mathrm{ACTICIDE}^{\circ} \mathrm{MBS}$ are mixtures of MIT (methylisothiazolinone) and BIT (benzisothiazolinone). The composition of ACTICIDE ${ }^{\circ}$ MBF 50 is also based on the formaldehyde donor, TMAD (tetra (hydroxymethyl) acetylenediurea). These biocides have very high efficiency of protection across a wide spectrum of aqueous formulations. ACTICIDE EPW is a biocide coating formulated from a mixture of a modified algicide, Diuron, in combination with fungicides. Such coatings are used to protect paint, plaster, adhesives, etc.

\section{Preparation and properties of suspended silver nanoparticles}

A suspension of silver nanoparticles ( $500 \mathrm{ppm})$ was obtained by chemical reduction of $\mathrm{Ag}^{+}$ions in an aqueous environment. Silver nitrate (V) (Sigma Aldrich, 99.90-99.99\%) was applied as a source of silver ions. An aqueous extract of dried raspberries was used as the source of chemical compounds having reducing and stabilizing properties. Sodium nitrate at a concentration of $0.01 \mathrm{~mol} / \mathrm{dm}^{3}$ was used as the $\mathrm{pH}$ regulator.

\begin{tabular}{|c|c|c|c|c|c|}
\hline \multirow[b]{2}{*}{$\begin{array}{l}\text { Sample } \\
\text { number }\end{array}$} & \multirow[b]{2}{*}{ Type of coating } & \multirow[b]{2}{*}{ Active substance } & \multicolumn{3}{|c|}{ Evaluation of fungal growth (final readings after 21 and 28 days of incubation) } \\
\hline & & & Repetitions & Average & $\begin{array}{l}\text { The criterion for acceptance: }<4 \text { according to the scale } \\
\text { (growth on up to } 50 \% \text { of the sample surface) }\end{array}$ \\
\hline 1 & Uni Grunt & silver nanoparticles $(1 \%)^{*}$ & $2 ; 4 ; 4 ; 4 ; 3 ; 3$ & 3.3 & positive \\
\hline 2 & Uni Grunt & ACTICIDE ${ }^{\circledR}$ MBS & $1 ; 2 ; 0 ; 0 ; 0 ; 1 ; 1 ; 3$ & 1 & positive \\
\hline 3 & Silicone plaster & silver nanoparticles $(1 \%)^{*}$ & $1 ; 1 ; 1 ; 1 ; 1$ & 1 & positive \\
\hline 4 & Silicone plaster & ACTICIDE $^{\circledR}$ MBS & $0 ; 0 ; 0 ; 0 ; 0$ & 0 & positive \\
\hline 5 & Silicone paint & silver nanoparticles $(1 \%)^{*}$ & $3 ; 3 ; 3 ; 3 ; 3$ & 3.0 & positive \\
\hline 6 & Silicone paint & ACTICIDE ${ }^{\circledR}$ MBS & $3 ; 2 ; 2 ; 3 ; 3$ & 2.6 & positive \\
\hline 7 & Silicone paint & silver nanoparticles $(2 \%)^{*}$ & $1 ; 1 ; 2 ; 2$ & 1.5 & positive \\
\hline 8 & Silicone paint & silver nanoparticles $(3 \%)^{*}$ & $2 ; 2 ; 2 ; 3$ & 2.3 & positive \\
\hline 9 & Silicone paint & $\begin{array}{l}\text { silver nanoparticles }(1 \%)^{*}+\text { ACTICIDE }^{\circledast} \\
\text { MBF } 50 \text { "in can" }(0.05 \%)\end{array}$ & $1 ; 3 ; 3$ & 2.3 & positive \\
\hline 10 & Silicone paint & $\begin{array}{l}\text { silver nanoparticles }(1 \%)^{\star}+\mathrm{ACTICIDE}^{\circledR} \\
\mathrm{EPW}(0.1 \%)\end{array}$ & $0 ; 0 ; 0 ; 0 ; 0$ & 0 & positive \\
\hline \multicolumn{5}{|c|}{ Final evaluation } & Criterion fulfilled \\
\hline
\end{tabular}

Table 1: Mycological efficacy results. 
A solution of chemical compounds having reducing and stabilizing properties was obtained from dried raspberries by leaching them in an aqueous phase. For this purpose, $4.5 \mathrm{~g}$ of dried raspberries and 500 $\mathrm{cm}^{3}$ of water were introduced into a round bottom flask with a reflux condenser. The flask was placed in a water bath $\left(30^{\circ} \mathrm{C}\right)$. The content was vigorously stirred for $5 \mathrm{~min}$. After this time the contents of the flask were filtered and the filtrate was retained.

In order to obtain a silver nanoparticle suspension, $20 \mathrm{~cm}^{3}$ of raspberry extract was added to $480 \mathrm{~cm}^{3}$ of an aqueous solution of silver nitrate $(\mathrm{V})\left(0.0048 \mathrm{~mol} / \mathrm{dm}^{3}\right)$ and the $\mathrm{pH}$ was adjusted to 10 using the $\mathrm{NaOH}$ solution. The mixture was stirred on a magnetic stirrer for $5 \mathrm{~min}$. The contents of the round bottom flask were transferred to a plastic container and allowed to stand at room temperature for 120 hours. The resulting suspension of silver nanoparticles was analysed using a UVVis spectrophotometer (UV1800 Rayleigh). The average particle size and zeta potential, $\xi$, were determined by a dynamic light scattering method (DLS, Zetasizer Nano ZS Malvern Instruments Ltd.).

\section{Characteristics of the nanosilver suspension}

The absorption spectra of nanosilver suspensions in the process of aging are shown in Figure 1. The peak at $400-450 \mathrm{~nm}$ corresponds to the characteristic surface plasmon resonance of silver nanoparticles. Surface plasmons are compatible oscillations of valence electrons of atoms on the material's surface. The absorption of radiation by metallic nanoparticles depends essentially on their size and shape. The plasmon band is not symmetrical, which means that the solutions contain aggregated particles. This is confirmed by the size distribution of the nanoparticles, which is presented in Figure 2. As a result of the process, silver nanoparticles with an average particle size of $57 \mathrm{~nm}$ and a $\xi$ potential $=-20 \mathrm{mV}$ were obtained.

\section{Mycological efficacy studies}

Tests of resistance to fungi were carried out according to EN 15457:2007 [26]. Test samples (about 2 g) were applied once with a Drigalski spatula on sterile filtration filters with a pore size of 0.45 microns so as to form a coating, which was later conditioned for 5 days at $23 \pm 2^{\circ} \mathrm{C}$ at a relative humidity of $50 \pm 5 \%$, according to EN 23270 [27]. Samples prepared in replicates were applied to the surface of malt medium (3\%) and agar (1.5\%). To determine the antifungal activity of the dry coating, each of the samples was inoculated with

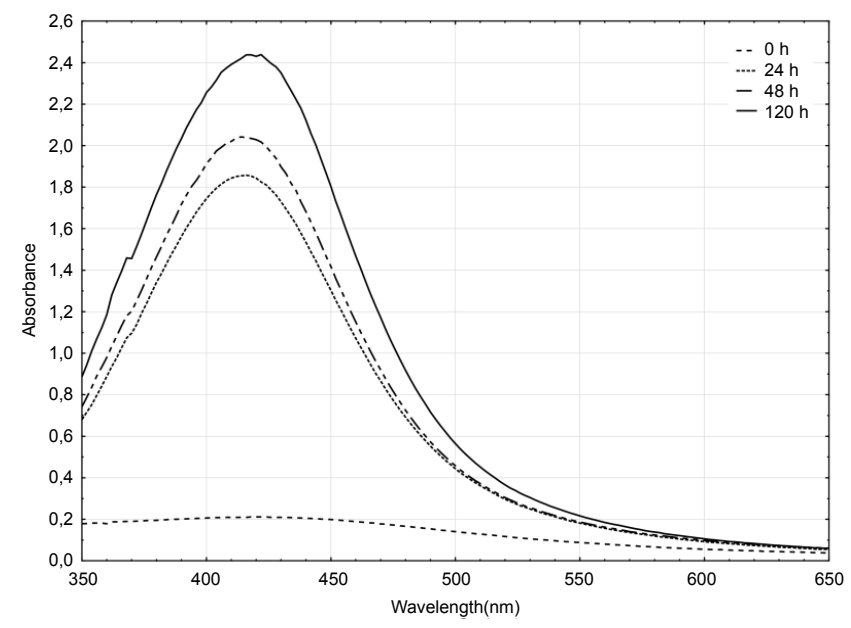

Figure 1: The absorption spectra of silver nanoparticles.
$0.2 \mathrm{~cm}^{3}$ of a mixture of a previously prepared suspension containing, in equal proportions in a total $10^{6}-10^{7} / \mathrm{cm}^{3}$, spores prone to fouling in the external environment - Cladosporiumclado sporioidesATCC 16022 and Alternaria alternata DSM 62010, with others prone fouling under internal conditions - Rhodotorulam ucilaginosaATCC 66034, Aspergillus Niger ATCC 16888 and Geotrichium candidum ATCC 34614 . The samples were incubated at $24 \pm 2^{\circ} \mathrm{C}$ for 21 days in accordance with the methodology of the research. Evaluation of the activity of the nanosilver in the test sample was based on a control test sample prepared containing biocides (Table 1). In accordance with the test method, the effectiveness of the coating was considered satisfactory if fungal growth occupied less than $50 \%$ of a tested sample - grade 3 according to the scale of the standard [26]:

0 - no fungus on the sample surface,

1 - mycelium growth on up to $10 \%$ of the surface,

2 - mycelium growth on greater than $10 \%$ but not more than $30 \%$ of the sample surface,

3 - mycelium growth on greater than $30 \%$ but not more than $50 \%$ of the sample surface,

4 - mycelium growth on greater than $50 \%$ of the sample surface.

\section{Results and Discussion}

All tested samples containing silver nanoparticles showed effective mycological resistance, comparable with the samples protected by biocides, garnering positive final assessmentsaccording the scale given in the EN 15457:2007 standard [26] (Table 1 and Figure 3).

The soil sample containing 1\% silver nanoparticles (mycelium growth greater than $30 \%$ but not more than $50 \%$ of the sample surface) received a grade of 3 , while the ground plaster with ACTICIDE ${ }^{\circ}$ MBS biocide was rated grade 1 (mycelium growth on up to $10 \%$ of the surface). There was no difference in the protection against fungi between silicone paint with a $1 \%$ content of silver nanoparticles and silicone paint with ACTICIDE ${ }^{\circledast}$ MBS because both samples were rated grade 3. Silicone paint with either a $2 \%$ or $3 \%$ silver nanoparticle content was characterized by very good efficacy of protection (grade 2), exceeding that of silicone paint with $\mathrm{ACTICIDE}^{\oplus} \mathrm{MBS}$ biocide (grade 3). The most satisfactory results were noted for plaster silicone with $1 \%$

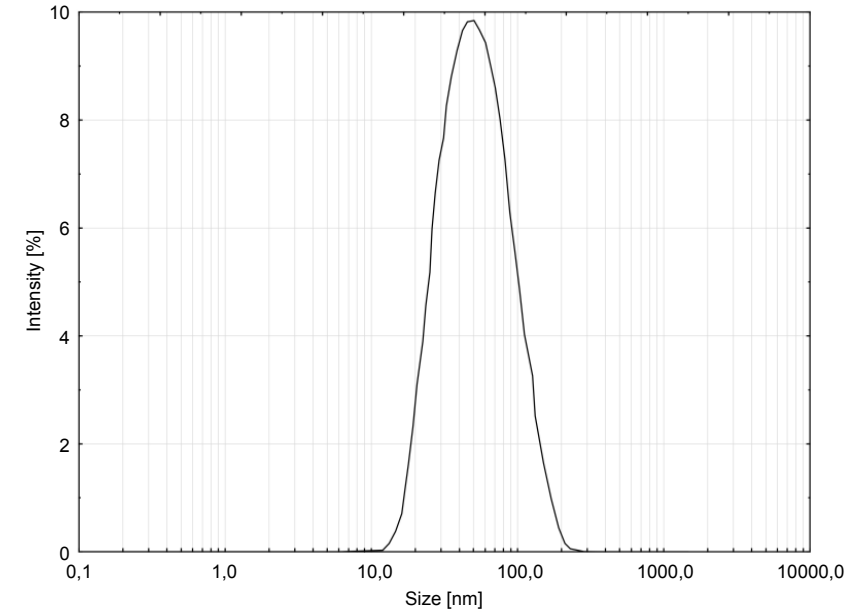

Figure 2: The size distribution of silver nanoparticles. 
Citation: Banach M, Szczygłowska R, Pulit J, Bryk M (2014) Building Materials with Antifungal Efficacy Enriched with Silver Nanoparticles. Chem Sci J 5: 085. doi: 10.4172/2150-3494.1000085

Page 4 of 5

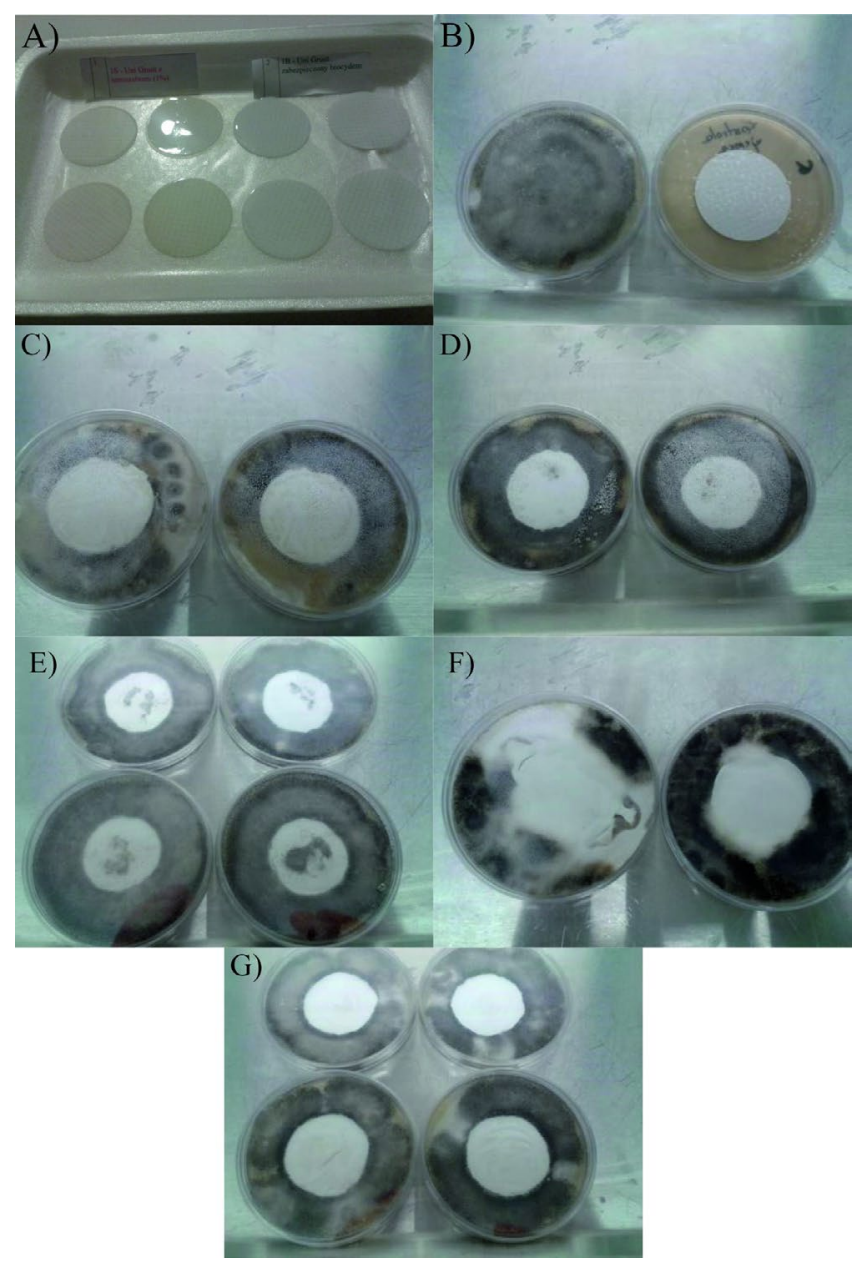

Figure 3: Photographs showing the samples analysed: A) prepared samples, B) positive and negative controls for fungal growth, C) silicone paint with nanosilver $(2 \%)$, growth $<10 \%$, D) silicone paint with nanosilver $(2 \%)$, growth between $10 \%$ and $30 \%$, E) silicone paint with nanosilver $(3 \%)$, growth from $10 \%$ to $30 \%$ and between $30 \%$ and $50 \%$, F) silicone paint protected by ACTICIDE $®$ MBS biocide, growth between $30 \%$ and $50 \%$ and between $10 \%$ and $30 \%$, G) $100 \%$ inhibition of fungal growth after 21 days with silicone plaster protected by a coating with nanosilver $(1 \%)$ and EPW $(0.1 \%)$.

silver nanoparticles, for plaster silicone with ACTICIDE ${ }^{\bullet}$ MBS and for the system with $1 \%$ silver nanoparticles and $0.1 \%$ ACTICIDE $^{\circ} \mathrm{EPW}$, whose evaluations were, respectively: 1,0 , and 0 .

According to the requirements [27], the positive control for fungal growth showed an increase from $50 \%$ to $100 \%$ on the 7 th day of the studies, getting a grade of 4 , which was the basis for reading the results at this time. However, in order to check the stability of the results obtained, the study was continued out to 21 days (optional conditions compatible with the standard). The results were stable for all samples except the sample of silicon paint with $1 \%$ silver nanoparticles and

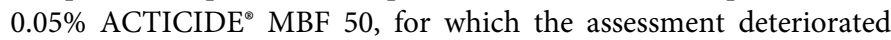
from 2 to 3 on the adopted scale but still met the requirements for an agent with antifungal properties. Additional readings were performed to confirm the stability after 28 days and they were consistent with readings after 21 days.

In view of this little recognized research area, the results can be referenced only to general research in this area and MIC and MBC values obtained for silver nanoparticles. Medical studies have reported that nanosilver exhibits high antifungal activity against Candida $s p p$ at a concentration of about $1 \mathrm{mg} / \mathrm{dm}^{3}$. Silver nanoparticles have fungicidal and fungi static effects on dermatophyte Trichophyton mentagrophytes and Candida spp [28-31]. There are also reports of the antifungal activity of the obtained silver nanoparticles during maintenance of materials for the production of footwear, wherein the $1 \%$ solution inhibited the growth of most strains of yeast-like fungi and moulds [30]. The recommended concentration of aqueous solutions containing nanostructured silver is $45 \mathrm{ppm}$. It acts as a biocide for $94 \%$ of the microorganisms isolated in museums and archives [6].

\section{Conclusion}

The antifungal activity of nanosilver in the checked products tested in accordance with EN 15457:2007 [26] was confirmed. The present study demonstrated the effectiveness of silver nanoparticles at a concentration of 1-3\%, corresponding to 5-15 ppm nanosilver.

The obtained protection matched or exceeded the results achieved by applying active fungicidal substances as biocides. The use of silver nanoparticles at a concentration of $2 \%$ or $3 \%$ in the silicone paint is particularly noteworthy, because the efficiency of its use outperformed the known biocide. The greatest efficiency of the protective coating was noted in a mixed system: silver nanoparticles (1\%) and ACTICIDE ${ }^{\circ}$ EPW (0.1\%) achieved $100 \%$ inhibition of tested fungi growth (Figure 3 ).

Nanostructured silver may be a promising alternative to currently used biocides.

The purpose of eco-labelling is to promote products that have limited impact on the environment. Pursuant to Regulation WE No. $1980 / 2000$, products must meet certain criteria for facade paints that are given in the British Standard BS 3900-G6:1989 "Methods of testing for paints. Assessment of resistance to fungal growth". The question remains whether the tested nanostructured silver also provides the required protective efficacy against fungi for external coatings. There is also a need to check the antibacterial activity of the tested nanosilver, in particular resistant strains, which will be the subject of further studies.

\section{Acknowledgements}

The work is part of a project "Synthesis and application of innovative nonmaterial's with antimicrobial properties" supported by National Centre for Research and Development under the contract no LIDER/03/146/L-3/11/ NCBR/2012 for the period of 2012-2015.

\section{References}

1. Flickinger MC, Drew SW (1999) Encyclopedia of Bioprocess Technology: Fermentation, Biocatalysis and Bioseparation. John Wiley \& Sons, Inc., New York.

2. Ghazy EA, Elmokadem MT, Gadallah M, Mahmoud MN, Abo Elsoud MM (2012) Combating Biocorrosion Induced by Biofilm Forming Bacterial Isolate Pseudomonas marginalis.Middle East J Sci Res 12: 1017-1025.

3. Bellotti N, Salvatore L, Deyá C, Del Panno MT, del Amo B, et al. (2013) The application of bioactive compounds from the food industry to control mold growth in indoor waterborne coatings. Colloids Surf B 104:140-144.

4. Schwab CJ, Straus DC (2004) The roles of Penicillium and Aspergillus in sick building syndrome. Adv Appl Microbiol 55: 215-238.

5. Cooley JD, Wong WC, Jumper CA, Straus DC (2004) Fungi and the indoor environment: Their impact on human health. Adv Appl Microbiol 55: 3-30.

6. Gutarowska B, Skora J, Zduniak K, Rembisz D (2012) Analysis of the sensitivity of microorganisms contaminating museums and archives to silver nanoparticles. Int Biodeterior 68: 7-17.

7. Council Directive 89/106/EEC of 21 December 1988 on the approximation of laws, regulations and administrative provisions of the Member States relating to construction products. 
Citation: Banach M, Szczygłowska R, Pulit J, Bryk M (2014) Building Materials with Antifungal Efficacy Enriched with Silver Nanoparticles. Chem Sci J 5: 085. doi: 10.4172/2150-3494.1000085

Page 5 of 5

8. Interpretative document to Directive 89/106. Essential Requirements No. 3 "Hygiene, health and environment", Warszawa 1994.

9. McDaniel CS, McDaniel J, Wales ME, Wild JR (2006) Enzyme-based additives for paints and coatings. Prog Org Coat 55: 181-188.

10. Wales ME, McDaniel CS, Everett AL, Rawlins JW, Blanton MD, et al. (2006) Next generation antimicrobial additives for reactive surface coatings. Paint Ctgsind 22: 62-70

11. Edge M, Allen NS, Turner D, Robinson J, Seal K (2001) The enhanced performance of biocidal additives in paints and coatings. Prog Org Coat 43 : $10-17$.

12. Konwar U, Karak N, Mandal M (2010) Vegetable Oil Based Highly Branched Polyester/Clay Silver Nanocomposites as Antimicrobial Surface Coating Materials. Prog Org Coat 68: 265-273.

13. Jämsa S, Mahlberg R, Holopainen U, Ropponen J, Savolainen A, et al. (2013) Slow release of a biocidal agent from polymeric microcapsules for preventing biodeterioration. Prog Org Coat 76: 269-276.

14. Jämsä S, Mahlberg R, Holopainen U, Ropponen J, Savolainen A, et al. (2010) Molecular release from painted surfaces: Free and encapsulated biocides. Prog Org Coat 69: 45-48.

15. Winowski K Biocide optimization: blends of actives. PCl and Paint and Coatings Industry, available on: http://www.pcimag.com/CDA/Archives (accessed 21.01.11).

16. Gaylarde CC, Morton LHG, Loh K, Shirakawa MA (2011) Biodeterioration of external architectural paint films - A review. Int Biodeterior 65: 1189-1198.

17. Cho KH, Park JE, Osaka T, Park SG (2005) The study of antimicrobial activity and preservative effects of nanosilver ingredient. Electrochim Acta 51: 956960.

18. Baker C, Pradhan A, Pakstis L, Pochan DJ, Shah SI (2005) Synthesis and antibacterial properties of silver nanoparticles. J Nano sci Nanotechnol 5: 244
19. Martínez-Castañón GA, Niño-Martínez N, Martínez-Gutierrez F, MartínezMendoza JR, Ruiz F (2008) Synthesis and antibacterial activity of silver nanoparticles with different sizes. J Nanoparticle Res 10: 1343-1348.

20. Morones JR, Elechiguerra JL, Camacho A, Holt K, Kouri JB, et al. (2005) The bactericidal effect of silver nanoparticles. Nanotechnology 16: 2346-2353.

21. Feng QL, Wu J, Chen GQ, Cui FZ, Kim TN, et al. (2000) A mechanistic study of the antibacterial effect of silver ions on Escherichia coli and Staphylococcus aureus. J Biomed Mater Res 52: 662-668.

22. Jung WK, Koo HC, Kim KW, Shin S, Kim SH, et al. (2008) Antibacterial activity and mechanism of action of the silver ion in Staphylococcus aureus and Escherichia coli. Appl Environ Microbiol 74: 2171-2178.

23. Smetana A, Klabunde KJ, George MR, Christopher MS (2008) Biocidal activity of nanocrystalline silver powders and particles. Langmuir 24: 7457-7464.

24. Panacek A, Kvitek L, Prucek R, Kolar M, Vecerova R, et al. (2006) Silver colloid nanoparticles: synthesis, characterization, and their antibacterial activity. J Phys Chem 110: 16248-16253.

25. Nanda A, Saravanan M (2009) Biosynthesis of silver nanoparticles from Staphylococcus aureus and its antimicrobial activity against MRSA and MRSE. Nanomedicine 5: 452-456.

26. EN 15457: 2007. Paints and varnishes - Laboratory method for testing the efficacy of film preservatives in a coating against fungi.

27. BS EN ISO 1513:1995 Paints and varnishes-Examination and preparation of samples for testing.

28. Kim KJ, Sung WS, Suh BK, Moon SK, Choi JS, et al. (2009) Antifungal activity and mode of action of silver nano-particles on Candida albicans. Biometals. Biometals 22: 235-242.

29. Kim KJ, Sung WS, Moon SK, Choi JS, Kim JG, et al. (2008) Antifungal effect of nanoparticles on dermatophytes. J Microbiol Biotechnol18: 1482-1484. 